\title{
CZE/PAD and HPLC-UV/PAD Profile of Flavonoids from Maytenus aquifolium and Maytenus ilicifolia "espinheira santa" Leaves Extracts
}

\author{
Cristina A. Diagone, Renata Colombo, Fernando M. Lanças, and Janete H. Yariwake \\ Instituto de Química de São Carlos, Universidade de São Paulo, Caixa Postal 780, 13560-970 São Carlos, SP, Brazil \\ Correspondence should be addressed to Janete H. Yariwake, janete@iqsc.usp.br
}

Received 22 June 2011; Accepted 9 October 2011

Academic Editor: Irena Vovk

Copyright ( 92012 Cristina A. Diagone et al. This is an open access article distributed under the Creative Commons Attribution License, which permits unrestricted use, distribution, and reproduction in any medium, provided the original work is properly cited.

This paper describes the application of HPLC and CZE to analyze flavonoids in the leaves of Maytenus ilicifolia and Maytenus aquifolium, which are species widely used in Brazilian folk medicine. The two species showed different flavonoid profiles, but acidic hydrolysis of the Maytenus extracts confirmed that all these compounds are quercetin or kaempferol derivatives. A comparison of the CZE and HPLC profiles of Maytenus extracts showed numerous flavonoid peaks using HPLC. However, the advantages of CZE such as analysis without requiring clean-up and less generation of chemical waste than with HPLC point to the potential of the CZE technique for the quality control (routine analysis) of "espinheira santa" phytopharmaceuticals.

\section{Introduction}

Flavonoids are a heterogeneous group of polyphenols (about 4000 substances) present in all plants and responsible for their color, growth, development, and immunity $[1,2]$ and can occur in free form (aglycones) or linked to sugars (glycosides) [3]. Many flavonoids found in plants have biological and pharmacological activities, such as antimicrobial, antiinflammatory, and antiallergic action [4-7]. The antioxidant property of these substances has also been established and correlated to their protective effects on cardiovascular disease and some forms of cancer [8-10].

Maytenus ilicifolia and M. aquifolium (Celastraceae) are Brazilian medicinal plants known as "espinheira santa", which are used in Brazil as phytopharmaceuticals due to their antiulcer activity $[11,12]$. Several studies focus on the bioactivity of Maytenus extracts, whose main compounds include flavonoid derivatives of quercetin and kaempferol $[13,14]$ and tannins [15]. These polyphenolic compounds can be correlated with the diverse pharmacological activities of these extracts $[16,17]$. Due to the structural characteristics of polyphenolic compounds, most of the procedures described in the literature for the analysis of $M$. aquifolium and
M. ilicifolia extract are based on RP-HPLC (reverse-phase high-performance liquid chromatography). Recently, however, a two-dimensional LC (size-exclusion-reverse-phase) procedure was employed for the LC-MS analysis of flavonol glycosides from $M$. ilicifolia leaves [18].

Due to its robustness, sensitivity, and versatility, HPLCUV/PAD (high performance liquid chromatography-ultraviolet detection using a photodiode array detector) is the technique of choice for the analysis of flavonoids and other phenolic compounds in natural products $[19,20]$. However, more recently, CE (capillary electrophoresis) techniques, including CZE (capillary zone electrophoresis), have been introduced as an analytical tool in studies of many secondary plant metabolites, mainly due to the method's faster development, lower operating cost and solvent consumption, and higher separation efficiencies $[19,21]$.

This work compares the HPLC and CZE techniques applied in the analysis of flavonoids contained in these two Maytenus species. Analytical methods for these two species that are suitable for application in agronomic studies or the quality control of phytopharmaceuticals, for example, require numerous analyses. In the development of these analytical methods, one must also keep in mind that the two 
aforementioned Maytenus species are known by the same popular name, "espinheira santa", but only M. ilicifolia is registered in the 4th Edition of the Brazilian Pharmacopoeia (2003) [22].

\section{Materials and Methods}

2.1. Plant Material. Leaves of Maytenus aquifolium Mart. and Maytenus ilicifolia (Schrad.) Planch. (Celastraceae) were supplied by Dr. Ana Maria Soares Pereira (UNAERP_-Universidade de Ribeirão Preto, Ribeirão Preto, SP, Brazil). These leaves were picked from specimens cultivated on the farm of the UNAERP campus; voucher specimens were deposited at the UNAERP herbarium and identified as HPMU-0755 ( $M$. aquifolium) and HPMU-0266 (M. ilicifolia). Immediately after the leaves were picked, they were dried at $40^{\circ} \mathrm{C}$ to constant weight, ground in domestic blender, and pulverized. Only particles of $0.5-1.0 \mathrm{~mm}$ were used for the extractions and were stored in glass flasks protected from light and humidity until required for analysis.

2.2. Reagents and Materials. Rutin, quercetin, and kaempferol standards were obtained from Sigma (St. Louis, MO, USA). HPLC-grade acetonitrile (ACN) and trifluoroacetic acid (TFA) were purchased from Mallinckrodt (Paris, Kentucky, USA). Analytical grade methanol (MeOH) and ethyl acetate (EtOAc) were purchased from Mallinckrodt (Xalostoc, State of Mexico, Mexico). Analytical grade chloroform $\left(\mathrm{CHCl}_{3}\right)$ was purchased from Merck (Rio de Janeiro, Brazil). TLC plates of silica gel 60, without fluorescent indicator, were purchased from Merck (Darmstadt, Germany). Analytical grade monobasic potassium phosphate $\left(\mathrm{KH}_{2} \mathrm{PO}_{4}\right)$ and sodium tetraborate decahydrate $\left(\mathrm{NaB}_{4} \mathrm{O}_{7} \cdot 10 \quad \mathrm{H}_{2} \mathrm{O}\right)$ were purchased from Reagen (Rio de Janeiro, Brazil). Analytical grade formic acid $(\mathrm{HCOOH})$, phosphoric acid $\left(\mathrm{H}_{3} \mathrm{PO}_{4}\right)$, hydrochloric acid $(\mathrm{HCl})$, sodium hydroxide $(\mathrm{NaOH})$, and polyethylene-glycol (PEG 400) were obtained from Synth (São Paulo, Brazil). Diphenylboric acid 2-aminoethylester $\left(\mathrm{C}_{14} \mathrm{H}_{16} \mathrm{BNO}\right)$ was purchased from Sigma (St. Louis, MO, USA). Water was purified in a Millipore Milli-Q Water Purification System (Eschborn, Germany). Hydrophobic Fluoropore (HF-PTFE) membranes $(0.5 \mu \mathrm{m})$ and HA membranes $(0.45 \mu \mathrm{m})$ in cellulose ester media were purchased from Millipore (São Paulo, Brazil).

2.3. Preparation of Samples. $1.0 \mathrm{~g}$ of the Maytenus leaves was extracted by maceration agitation with $10 \mathrm{~mL}$ of $\mathrm{MeOH} / \mathrm{H}_{2} \mathrm{O}$ $(1: 1 \mathrm{v} / \mathrm{v})$ for $30 \mathrm{~min}$ at $50^{\circ} \mathrm{C}$. The hydromethanolic extracts were filtered, and their final volume was adjusted to $10 \mathrm{~mL}$ with $\mathrm{MeOH} / \mathrm{H}_{2} \mathrm{O}(1: 1 \mathrm{v} / \mathrm{v})$. No clean-up was necessary for the CZE analysis: the hydromethanolic extracts were simply filtered through $0.5 \mu \mathrm{m}$ HF-PTFE membranes (Millipore) and analyzed. For the HPLC analysis, the extracts were subjected to liquid-liquid extraction using $5 \mathrm{~mL}$ of $\mathrm{CHCl}_{3}$; the organic layer was discarded, and the hydromethanolic layer was filtered through $0.5 \mu \mathrm{m}$ HF-PTFE membranes (Millipore) before the HPLC analysis.
2.4. Preparation of Standards. $0.01 \mathrm{~g}$ of each flavonol standard (rutin, quercetin, or kaempferol) was dissolved separately in $10 \mathrm{~mL}$ of $\mathrm{MeOH}$. An aliquot of $0.1 \mathrm{~mL}$ of each stock solution was diluted to $10 \mathrm{~mL}$ with $\mathrm{MeOH}$ to obtain a stock solution containing the three flavonols; this stock solution was utilized in the HPLC and CZE analyses.

2.5. Thin Layer Chromatography. Analyses were carried out on silica gel 60 aluminum sheets precoated with EtOAc/ $\mathrm{HCOOH} / \mathrm{H}_{2} \mathrm{O}(6: 1: 1 \mathrm{v} / \mathrm{v})$. After developing the plates, the solvent was dried and the flavonoids were visualized with diphenylboric acid 2-aminoethylester-PEG 400 under UV at $\lambda=360 \mathrm{~nm}[23]$.

2.6. Acid Hydrolysis. Maytenus extract was evaporated to $8.3 \mathrm{~mL}$ and mixed with $1.7 \mathrm{~mL}$ of $2.0 \mathrm{~mol} / \mathrm{L} \mathrm{HCl}$. The solution was refluxed for $10 \mathrm{~min}$ at $95^{\circ} \mathrm{C}$. The resulting extracts were filtered through $0.5 \mu \mathrm{m}$ HF-PTFE membranes (Millipore) and analyzed by HPLC.

2.7. CZE Analysis. The CZE analysis was performed in an $\mathrm{HP}^{3 \mathrm{D}}$ Capillary Electrophoresis System (Hewlett Packard, Waldbronn, Germany) equipped with a photodiode array (Hewlett Packard) and an HP Chem Station data processing system. Separations were performed using an uncoated fused silica capillary tube (Polymicro Technologies, Phoenix, AZ, USA) with a total length of $64.5 \mathrm{~cm}$, effective length of $56.0 \mathrm{~cm}$, and i.d. of $50.0 \mu \mathrm{m}$. Samples were injected in hydrostatic mode at $500 \mathrm{mbar}$ for $7 \mathrm{~s}$. The analysis was performed at $25^{\circ} \mathrm{C}$ and an applied voltage of $20 \mathrm{kV}$, and the samples were introduced into the system in hydrostatic mode at $500 \mathrm{mbar}$ pressure for $7 \mathrm{~s}$. Capillary conditioning was carried out by first washing with $\mathrm{H}_{2} \mathrm{O}$ for $10 \mathrm{~min}$, followed by $1.0 \mathrm{~mol} / \mathrm{L}$ $\mathrm{NaOH}$ for $5 \mathrm{~min}, 0.1 \mathrm{~mol} / \mathrm{L} \mathrm{NaOH}$ for $5 \mathrm{~min}$, and finally with the running buffer for $10 \mathrm{~min}$. Between consecutive runs, the capillary tube was flushed with $0.1 \mathrm{~mol} / \mathrm{L} \mathrm{NaOH}$ for $5 \mathrm{~min}$ and running buffer for $5 \mathrm{~min}$. Buffer solutions of sodium tetraborate and potassium phosphate in water were prepared, and the $\mathrm{pH}$ was adjusted using phosphoric acid or $\mathrm{NaOH}$ solutions. Optimal separation conditions were determined after testing different buffer conditions: concentration of tetraborate-phosphate (resp., 50:5; 30:5; 30:25; 30:50, $10: 5 \mathrm{mmol} / \mathrm{L})$ and $\mathrm{pH}$ values $(8.0 ; 8.5 ; 9.0 ; 9.3 ; 9.5,10.0)$, as well as the percentage of methanol $(2.0 ; 5.0 ; 8.0,12.0 \%)$ used as organic solvent.

2.8. HPLC-UV-PAD Analysis. This analysis was performed in a modular LC System (Shimadzu, Kyoto, Japan) consisting of two LC-10 AD pumps; a CTO-10A column oven; an SPDM10A variable wavelength diode array detector; the LC-10 Workstation Class data processing system. Supelcosil columns (Supelco, Bellefonte, PA, USA) with stationary phase C-18 and C-8 columns $(250 \mathrm{~mm} \times 4.6 \mathrm{~mm}, 5 \mu \mathrm{m})$ protected by guard columns filled with the same stationary phase $(20 \mathrm{~mm} \times 4.6 \mathrm{~mm}, 5 \mu \mathrm{m})$ were utilized. The column oven was thermostat controlled at $35^{\circ} \mathrm{C}$, and the flow rate was $1.0 \mathrm{~mL} /$ min. The injection volume was $10 \mu \mathrm{L}$ (Rheodyne loop). Detection was monitored at 254 and $350 \mathrm{~nm}$. The mobile phases tested were: (A) 2.0, 2.5 and 3.0\% formic acid in water and $0.3 \%$ trifluoroacetic acid in water; (B) ACN or MeOH. 


\section{Results and Discussion}

Prior to the HPLC analysis, the Maytenus extracts were subjected to TLC analysis. M. aquifolium extracts showed two spots with lower Rf values (= more polar compounds) than quercetin and kaempferol standards. The fluorescence of these spots indicated the presence of quercetin derivatives (orange fluorescent spots) and kaempferol derivatives (green fluorescent spots) [23]. M. ilicifolia extracts exhibited six glycoside flavonols derivatives of quercetin (one of them with Rf identical to that of rutin) and two glycoside flavonol derivatives of kaempferol. These compounds have higher Rf values and are therefore less polar than the two glycoside flavonols reported in M. aquifolium extracts [24, 25].

3.1. HPLC-UV-PAD Analysis. Optimization of the chromatographic conditions showed that the $\mathrm{C}-18$ and $\mathrm{C}-8$ columns were highly efficient in the separation of flavonoids from Maytenus. However, for M. aquifolium extracts, the C-18 column provided better resolution in the separation of flavonoids. The amount of formic acid (2.0\% in water, solvent A) was chosen because the increase in the percentage of formic acid (2.5 and 3.0\%) and its replacement with trifluoroacetic acid did not improve the resolution and led to similar separation efficiencies. Acetonitrile showed better results than methanol and was therefore selected as the organic solvent in the optimized HPLC conditions for the extracts of the two Maytenus species.

The HPLC-UV/PAD analysis led to the detection of two flavonoids in M. aquifolium leaves (Figure 1).

The flavonoid peaks can be identified by their characteristic UV/PAD spectral pattern with two bands, Band I, $\lambda_{\max }$ around $300-380 \mathrm{~nm}$ and Band II, $\lambda_{\max }$ around $240-280 \mathrm{~nm}$. Moreover, quercetin derivatives $\left(\lambda_{\max }=354 \mathrm{~nm}\right)$ can be distinguished from kaempferol derivatives $\left(\lambda_{\max }=344 \mathrm{~nm}\right)$ also considering the data obtained by TLC and the acid hydrolysis of Maytenus extracts [26]. Therefore, the comparison of the material obtained by acid hydrolysis (Figure 2(a)) with authentic standards (Figure 2(b): retention time of the aglycones and UV-PAD spectra) confirmed quercetin and kaempferol as the aglycones of M. aquifolium flavonoids.

In the chromatogram of Maytenus ilicifolia leaf extracts (Figure 3), twelve peaks show UV/PAD spectra characteristic of flavonoids. Peaks 1 to 4,7 , and 9 to 12 are quercetin derivatives $\left(\lambda_{\max } \sim 354 \mathrm{~nm}\right)$ while peaks 5 and 6 are kaempferol derivatives $\left(\lambda_{\max } \sim 344 \mathrm{~nm}\right)$.

Peak 8 was identified as rutin by direct comparison (retention time and UV-DAD spectra) with an authentic commercial standard (Figure 4). The acid hydrolysis of extract also confirmed quercetin and kaempferol as aglycones of M. ilicifolia flavonoids, which are identified in Figure 5.

3.2. CZE Analysis. Figures 6 and 7 illustrate the optimized conditions for CZE analysis of M. aquifolium and M. ilicifolia, respectively. The CZE/DAD-UV electropherogram of $M$. aquifolium showed the presence of two major compounds, peaks 1 and 2, respectively, identified as kaempferol and quercetin derivatives (Figure 6), plus other minor

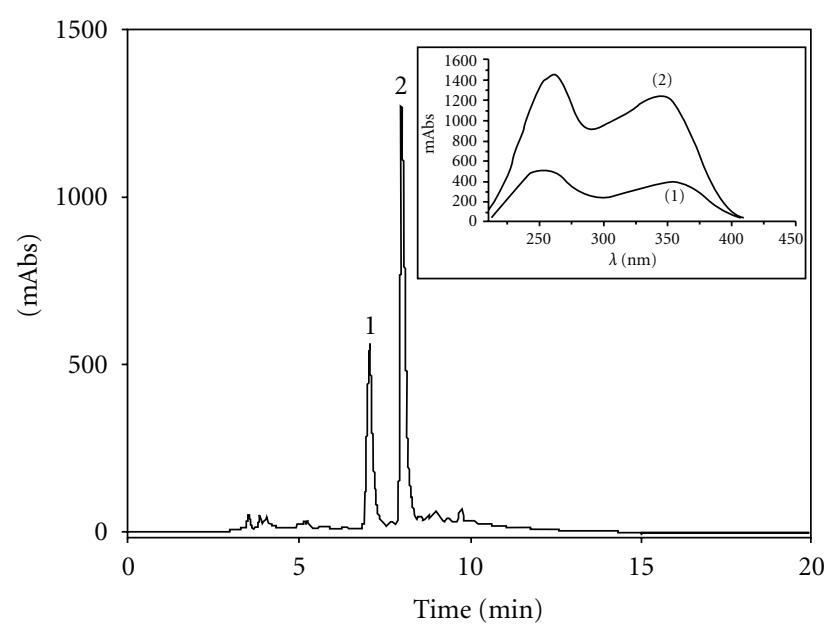

FIGURE 1: HPLC/DAD-UV $(\lambda=270 \mathrm{~nm})$ chromatogram of flavonoids from M. aquifolium leaves. (1) Quercetin derivative and (2) kaempferol derivative. Mobile phase: $0-20$ min 15-80\% acetonitrile (solvent B); for other chromatographic conditions, see experimental part.

flavonoids not detected in the HPLC-UV/DAD chromatogram. The electropherogram of M. ilicifolia in Figure 7, which was obtained at $\lambda=380 \mathrm{~nm}$ due to the interference of other compounds at $\lambda=270 \mathrm{~nm}$ (possibly phenolic compounds), indicates the presence of ten flavonoids, including rutin. The presence of rutin was suggested by TLC analysis and confirmed by spiking M. ilicifolia extract. Moreover, the longer migration time of this compound compared to the two major flavonoids (peaks 1 and 2, Figure 7) indicates that these major peaks are more polar compounds, possibly the triglycosylated flavonoids reported in M. aquifolium extracts $[24,25]$.

The CZE separation was optimized based on the parameters of $\mathrm{pH}$, buffer concentration, and the effect of modifier. An important parameter is $\mathrm{pH}$, which changes the electroosmotic flow (EOF) and affects the degree of ionization of the solutes. The electrophoretic mobility $\left(\mu_{\mathrm{ef}}\right)$ and migration times $\left(t_{\mathrm{M}}\right)$ of three flavonol standards - rutin, quercetin, and kaempferol-were calculated to verify the electrophoretic behavior of Maytenus extracts (Table 1). The results indicate that the increase in $\mathrm{pH}$ values augmented both the $\mu_{\mathrm{ef}}$ and migration times of all flavonoids, while lower values $\mathrm{pH}$ showed a decrease in $\mu_{\mathrm{ef}}$, resulting in a decrease in the negative charges of the compounds.

Figure 8 illustrates the effect of $\mathrm{pH}$ on the $\mu_{\mathrm{ef}}$ of flavonol standards. The differences in their $\mu_{\text {ef }}$ were attributed to differences in molecular size and in the number and acidity (pKa) of the free phenolic groups attached to the flavonoid skeleton, which contribute to different levels of charge in flavonol molecules due to differences in acidity. A pH of 8.5 was chosen for the CZE analysis of both Maytenus extracts due to the higher efficiency and resolution and faster analysis. An analysis was made of the influence of tetraborate and phosphate concentrations on the CZE analysis (Table 2).

The results showed that the decrease in tetraborate concentration diminished the resolution in the separation of 


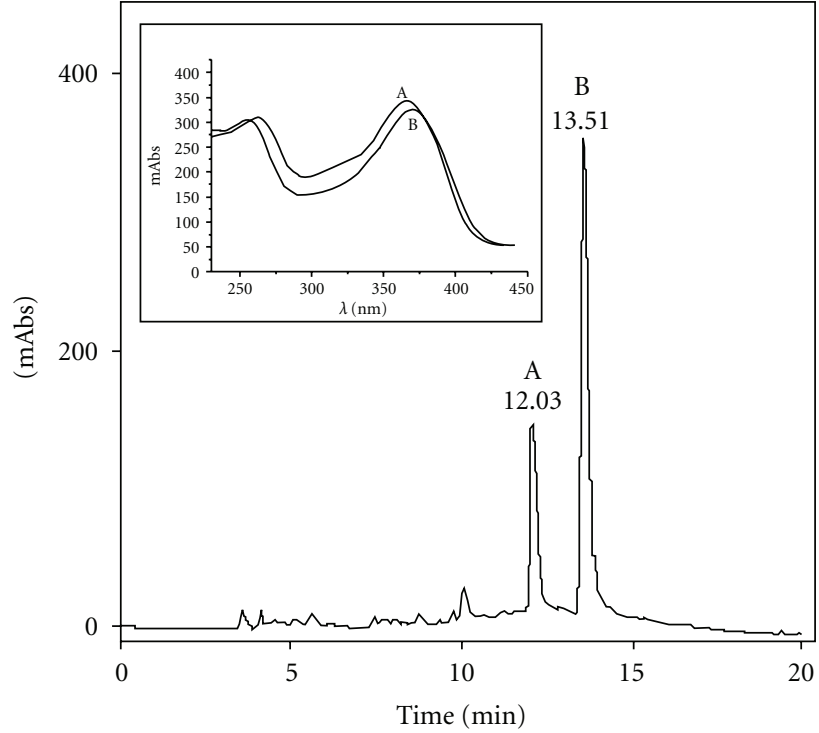

(a)

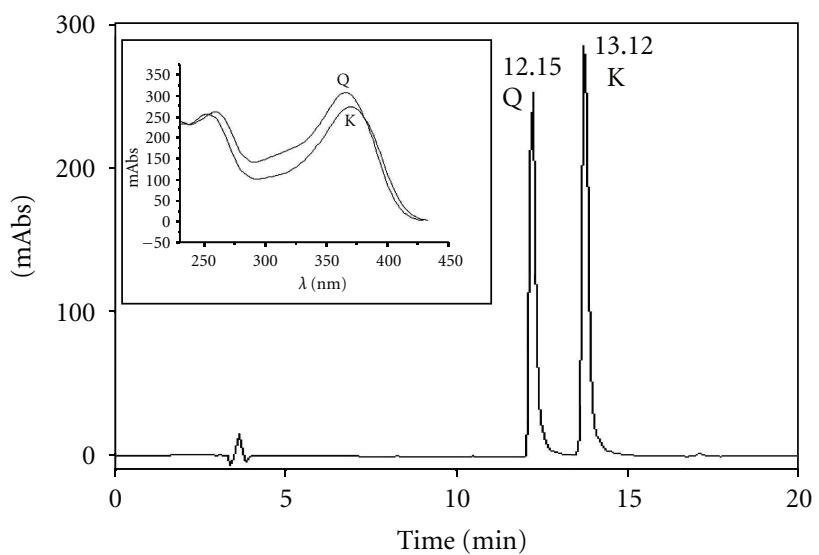

(b)

FIgURE 2: HPLC/DAD-UV $(\lambda=270 \mathrm{~nm})$ chromatogram and UV-PAD spectra of (a) M. aquifolium leaves extract after acid hydrolysis and (b) standards quercetin $(\mathrm{Q})$ and kaempferol (K). Mobile phase: 0-20 min 15-80\% acetonitrile; for other chromatographic conditions, see experimental part.

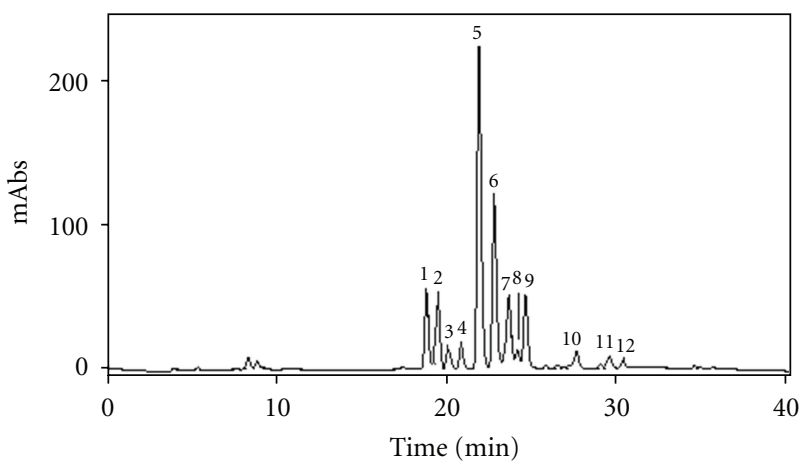

(a)

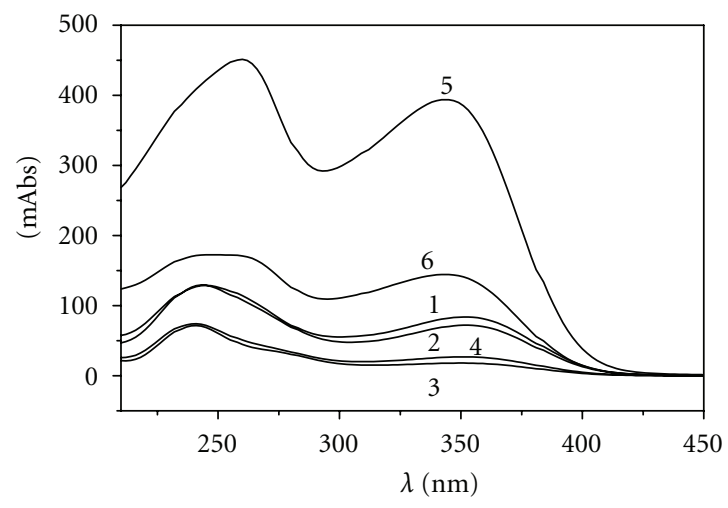

(b)

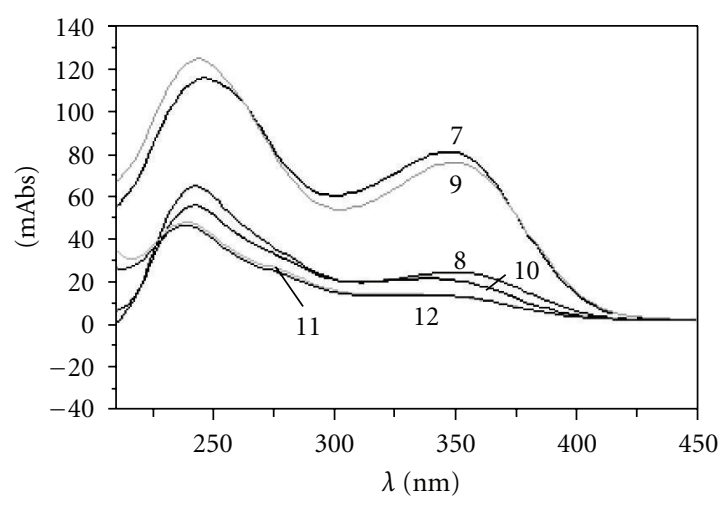

(c)

Figure 3: HPLC/DAD-UV $(\lambda=380 \mathrm{~nm})$ chromatogram and UV-PAD spectra of flavonoids from M. ilicifolia leaves. Peaks 1-4, 7, and 9-12: quercetin derivatives, peaks 5 and 6: kaempferol derivatives. Peaks 8: rutin. Mobile phase: 0-2 min 10\% acetonitrile (solvent B), 2-15 min $10-15 \%$ B, 11-22 min 15-18\% B, 22-37 min 18-30\% B, 37-42 min 30-40\% B; for other chromatographic conditions, see experimental part. 
TABLE 1: Effect of $\mathrm{pH}$ variation on the values of migration time $\left(t_{\mathrm{M}}\right)$ and electrophoretic mobility $\left(\mu_{\mathrm{ef}}\right)$ of flavonoid standards: (1) rutin, (2) kaempferol, and (3) quercetin. Buffer: tetraborate $30 \mathrm{mmol} / \mathrm{L} /$ phosphate $5 \mathrm{mmol} / \mathrm{L}$. For detailed CZE conditions, see experimental section.

\begin{tabular}{lcccccc}
\hline $\mathrm{pH}$ & $t_{\mathrm{M}(1)}(\mathrm{min})$ & $t_{\mathrm{M}(2)}(\mathrm{min})$ & $t_{\mathrm{M}(3)}(\mathrm{min})$ & $\mu_{\mathrm{ef}(1)} \times 10^{-4}\left(\mathrm{~cm}^{2} \mathrm{~V} \cdot \mathrm{s}\right)$ & $\mu_{\mathrm{ef}(2)} \times 10^{-4}\left(\mathrm{~cm}^{2} \mathrm{~V} \cdot \mathrm{s}\right)$ & $\mu_{\mathrm{ef}(3)} \times 110^{-4}\left(\mathrm{~cm}^{2} \mathrm{~V} \cdot \mathrm{s}\right)$ \\
\hline 8.0 & 9.625 & 8.983 & 12.399 & 1.671 & 1.433 & 2.372 \\
8.5 & 9.512 & 9.597 & 12.613 & 1.651 & 2.679 & 2.430 \\
9.0 & 9.347 & 10.587 & 12.869 & 1.850 & 2.43 & 2.733 \\
9.3 & 10.040 & 12.537 & 14.576 & 1.837 & 2.628 & 2.772 \\
9.5 & 10.248 & 13.742 & 15.375 & 1.880 & 2.954 & 3.861 \\
10.0 & 11.475 & 18.693 & 19.741 & 1.940 & & 3.040 \\
\hline
\end{tabular}

$\mu_{\mathrm{ef}}=\left(L_{\mathrm{t}} \times L_{\mathrm{ef}}\right) /\left(t_{\mathrm{m}} \times V\right)-\left(L_{\mathrm{t}} \times L_{\mathrm{ef}}\right) /\left(t_{\mathrm{nm}} \times V\right)$, where $L_{\mathrm{t}}$ is the total lenght of the capillary, $L_{\mathrm{ef}}$ is the effective lenght of the capillary, $t_{\mathrm{m}}$ is the migration time of the analyte, $t_{\mathrm{nm}}$ is the migration time of the neutral marker (methanol), and $V$ is the applied voltage.

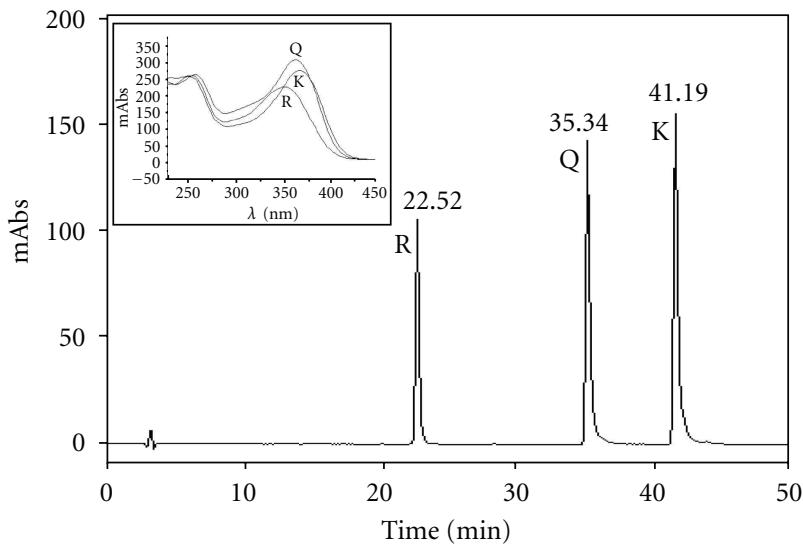

Figure 4: HPLC/DAD-UV $(\lambda=380 \mathrm{~nm})$ chromatogram and UVPAD spectra of standards rutin, quercetin, and kaempferol. Mobile phase: $0-2 \min 10 \%$ acetonitrile (solvent B), $2-15 \min 10-15 \% \mathrm{~B}$, $11-22 \min 15-18 \%$ B, 22-37 min $18-30 \%$ B, 37-42 min 30-40\% B; for other chromatographic conditions, see experimental part.

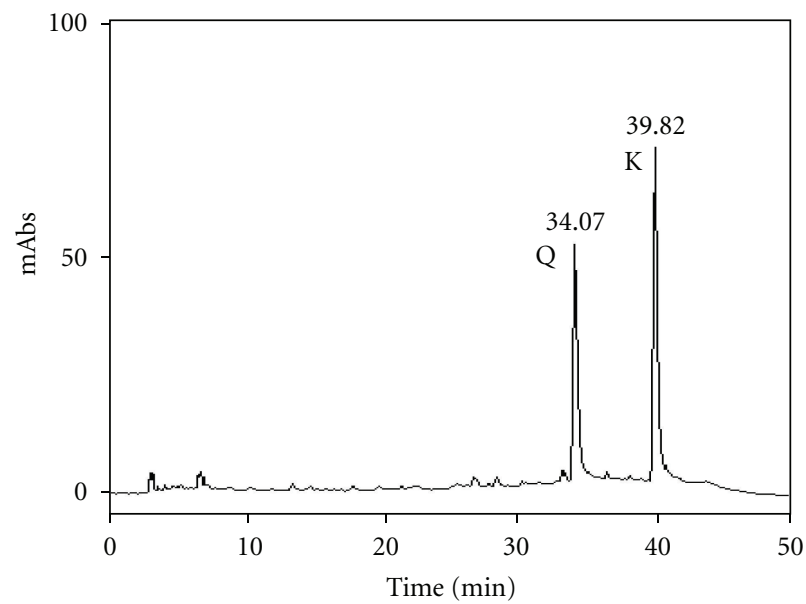

FIGURE 5: HPLC/DAD-UV $(\lambda=380 \mathrm{~nm})$ chromatogram of $M$. ilicifolia leaves extract after acid hydrolysis. Mobile phase: $0-2 \mathrm{~min} 10 \%$ acetonitrile (solvent B), 2-15 min 10-15\% B, 11-22 min 15-18\% B, 22-37 min $18-30 \%$ B, 37-42 min 30-40\% B; for other chromatographic conditions, see experimental part.

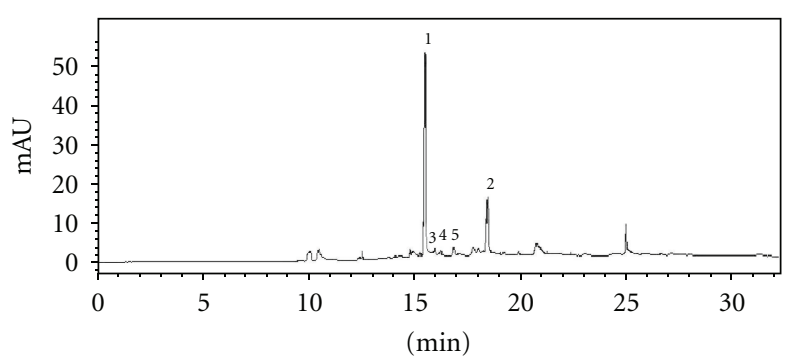

FIGURE 6: CZE/DAD-UV electropherogram of Maytenus aquifolium leaves extract $(\lambda=270 \mathrm{~nm})$. Peak 1: kaempferol derivative; peak 2: quercetin derivative; peaks 3-5: other minor flavonoids. Conditions: buffer $30 \mathrm{mmol} / \mathrm{L}$ tetraborate, $50 \mathrm{mmol} / \mathrm{L}$ phosphate, $\mathrm{pH}=$ $8.5,20 \mathrm{kV}$, and $12 \% \mathrm{MeOH}$; for other electrophoretic conditions, see experimental part.

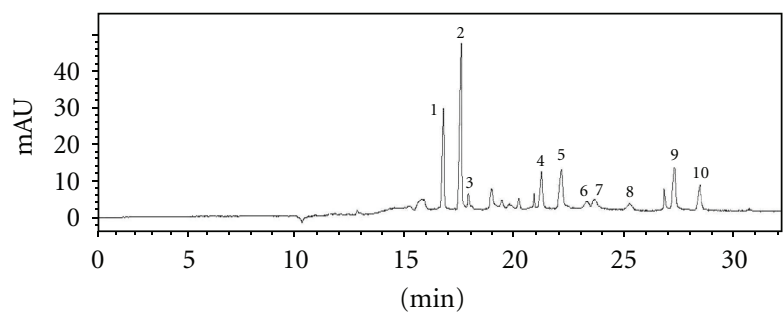

FIGURE 7: CZE/DAD-UV electropherogram of Maytenus ilicifolium leaves extract $(\lambda=380 \mathrm{~nm})$. Conditions: buffer $30 \mathrm{mmol} / \mathrm{L}$ tetraborate, $50 \mathrm{mmol} / \mathrm{L}$ phosphate, $\mathrm{pH}=8.5,20 \mathrm{kV}$, and $12 \% \mathrm{MeOH}$, for other electrophoretic conditions, see experimental part.

the flavonol glycosides due to the minor presence of tetraborate complexes at this concentration. On the other hand, increasing the tetraborate and phosphate concentrations led to a decrease in EOF and an increase in migration time due to the higher viscosity of the buffer. The resolution was calculated using the peaks of kaempferol and quercetin derivatives (major flavonoids), and the best results were achieved with $50 / 50 \mathrm{mmol} / \mathrm{L}$ tetraborate/phosphate. However, 30/ $50 \mathrm{mmol} / \mathrm{L}$ tetraborate/phosphate showed better separation if one also considers the minor flavonoids, so the latter proportion was chosen as the optimum condition for both Maytenus extracts. 


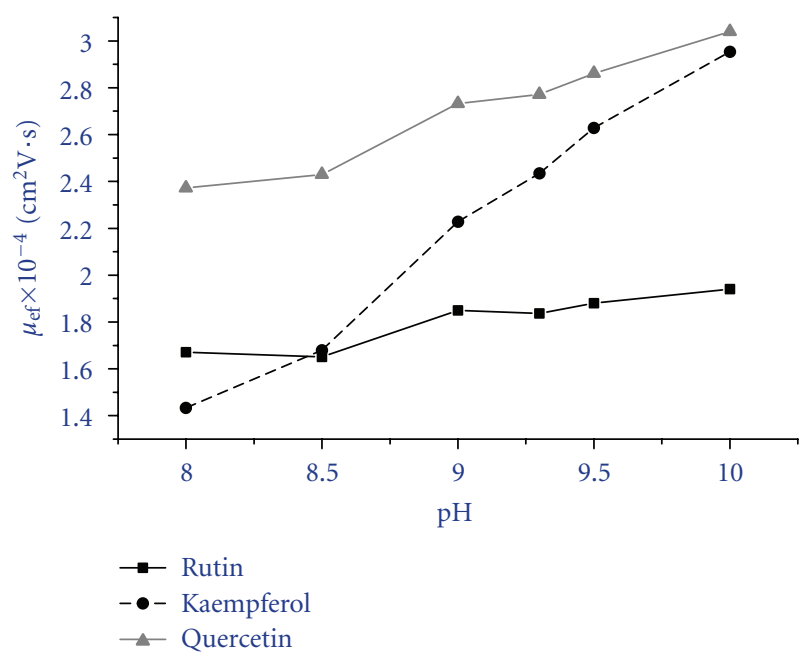

FIGURE 8: Effect of $\mathrm{pH}$ on electrophoretic mobility of flavonols standards (rutin, quercetin, kaempferol). Conditions: buffer $30 \mathrm{mmol} / \mathrm{L}$ tetraborate, $50 \mathrm{mmol} / \mathrm{L}$ phosphate; for other electrophoretic conditions, see experimental part.

TABLE 2: Resolution (Rs) between the peaks corresponding to the quercetin and kaempferol derivatives found in Maytenus aquifolium extracts (resp., peaks 1 and 2 at Figure 1), at $\mathrm{pH} 8.5$ and with variation of buffer tetraborate/phosphate concentration.

\begin{tabular}{ll}
\hline Concentration of tetraborate/phosphate $(\mathrm{mmol} / \mathrm{L})$ & $\mathrm{Rs}_{1,2}$ \\
\hline $10 / 5$ & Coelution \\
$30 / 5$ & 5.506 \\
$50 / 5$ & 6.320 \\
$30 / 25$ & 5.941 \\
$30 / 50$ & 6.311 \\
\hline $\mathrm{Rs}=(1 / 4) N^{1 / 2}\left(\Delta \mu_{\mathrm{ef}} /\left(\overline{\mu_{\mathrm{ef}}}+\mu_{\mathrm{eof}}\right)\right)$, where $\Delta \mu_{\mathrm{ef}}$ is the difference on the \\
electrophoretic mobility of the two analytes; $\mu_{\mathrm{ef}}$ is the mean of mobility of \\
compounds corresponding to peaks 1 and $2 ; \mu_{\mathrm{eof}}$ is the mobility of the \\
eletroosmotic flow (neutral marker: methanol).
\end{tabular}

Figures 9 and 10 illustrate the effect of different percentages of methanol as organic modifier: the use of $12 \%$ methanol increased the migration times of the analytes. Moreover, methanol increased the resolution for some flavonoids that coeluted in the absence of organic modifier (peaks 3 to 5, Figure 6, possible flavonols) in M. aquifolium. Similar results were observed in $M$. ilicifolia extracts, with the separation of peaks 6 (rutin) and 7; hence, the optimized conditions for both extracts (Figures 6 and 7) include 12\% methanol.

\section{Conclusions}

The HPLC and CZE techniques can both be used in the analysis of flavonoids in Maytenus aquifolium and Maytenus ilicifolia extracts. The comparison of the results obtained by these techniques showed that CZE offers some advantages, for example, higher efficiency and resolution, shorter separation time, and the fact that CZE does not require cleanup of the extracts. Furthermore, the CZE method is an

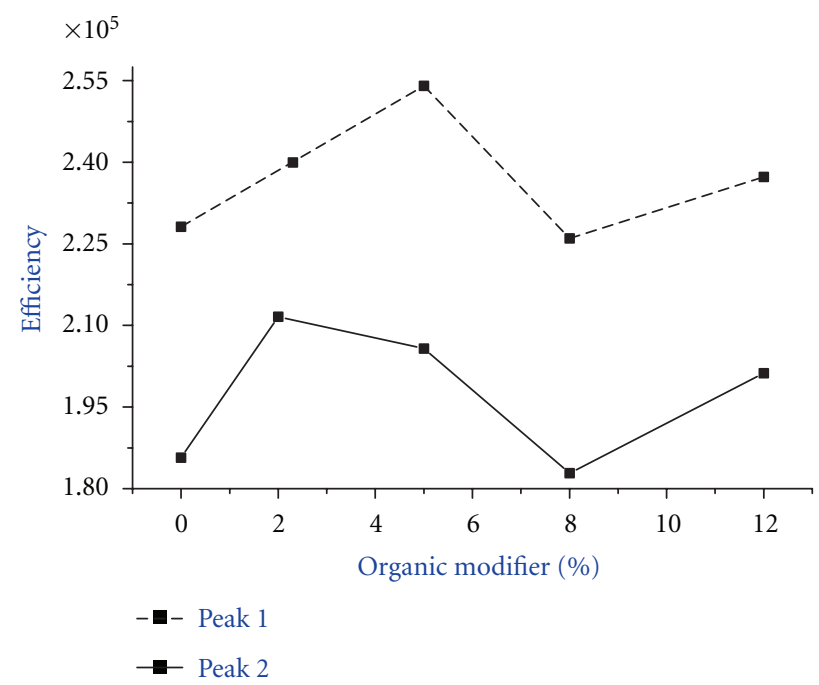

FIGURE 9: Effect of percentage organic modifier on efficiency $(\mathrm{N})$ in the CZE analysis of Maytenus aquifolium leaves extract (see Figure 6 for electropherogram and identification of the peaks).

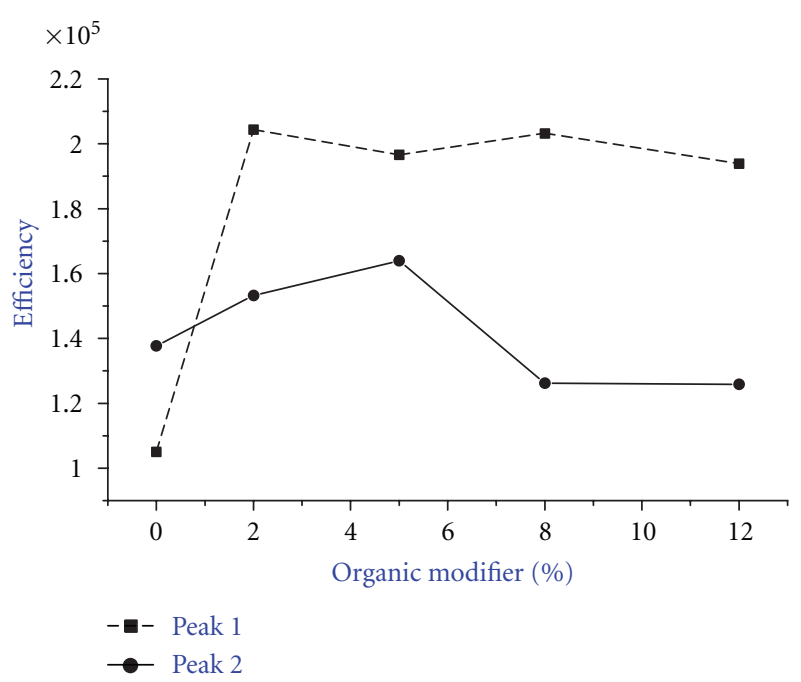

FIGURE 10: Effect of percentage organic modifier on efficiency (N) in the CZE analysis of Maytenus ilicifolium leaves extract (see Figure 7 for electropherogram and identification of the peaks).

"ecofriendly", "green" analytical method, which was confirmed by the fact that the optimized conditions allowed for the elimination of acetonitrile from the mobile phase, a significant benefit considering its toxicity. These advantages suggest that CZE should be more widely exploited as an analytical method, for example, in the quality control of "espinheira santa" phytopharmaceuticals, particularly considering the huge amounts of chemical waste produced by the pharmaceutical industry in routine analyses. On the other hand, HPLC showed greater efficacy in the detection of flavonols, since twelve flavonols were detected using this technique while only ten flavonols were detected in the optimized CZE conditions. 


\section{Acknowledgments}

The authors thank Dr. Ana Maria Soares Pereira for kindly supplying plant material, Professor Dr. Emanuel Carrilho for the discussions about CZE, and FAPESP (98/04334-9, 00/ 11645-2, 02/00493-2, and 06/59457-6), CNPq, and CAPES for granting fellowships and financial support.

\section{References}

[1] J.B. Harborne, The Flavonoids, Chapman and Hall, London, UK, 1994.

[2] M. T. L. Ielpo, A. Basile, R. Miranda et al., "Immunopharmacological properties of flavonoids," Fitoterapia, vol. 71, no. 1, pp. 101-109, 2000.

[3] K. R. Markham, Techniques of Flavonoid Identification, Academic Press, New York, NY, USA, 1982.

[4] C. Salvatore, "The role of quercetin, flavonols and flavones in modulating inflammatory cell function," Inflammation \& Allergy, vol. 9, pp. 263-285, 2010.

[5] J. Gonzalez-Gallego, M. V. Garcia-Mediavilla, S. SánchezCampos, and M. J. Tuñó, "Fruit polyphenols, immunity and inflammation," Journal of Nutrition, vol. 104, supplement 3, pp. S15-S27, 2010.

[6] S. Kesarkar, A. Bhandage, S. Deshmukh, K. Shevkar, and M. Abhyankar, "Flavonoids: an overview," Journal of Pharmacy Research, vol. 2, pp. 1148-1154, 2009.

[7] M. A. S. Coutinho, M. F. Muzitano, and S.S. Costa, "Flavonoids: potential therapeutic agents for the inflammatory process," Revista Virtual de Quimica, vol. 1, pp. 241-256, 2009.

[8] E. P. Scholz, E. Zitron, H. A. Katus, and C. A. Karle, "Cardiovascular ion channels as a molecular target of flavonoids," Cardiovascular Therapeutics, vol. 28, no. 4, pp. e46-e52, 2010.

[9] T. R. Cibin, D. Gayathri Devi, and A. Abraham, "Chemoprevention of skin cancer by the flavonoid fraction of Saraca asoka," Phytotherapy Research, vol. 24, no. 5, pp. 666-672, 2010.

[10] R. K. Parabathina, G. V. Raja, M. N. Rao, G. S. Rao, and K. S. Rao, "Cardioprotective effects of vitamin E, morin, rutin and quercetin against doxorubicin induced oxidative stress of rabbits: a biochemical study," Journal of Chemical and Pharmaceutical Research, vol. 2, pp. 754-765, 2010.

[11] R. M. Jorge, J. P. V. Leite, A. B. Oliveira, and C. A. Tagliati, "Evaluation of antinociceptive, anti-inflammatory and antiulcerogenic activities of Maytenus ilicifolia," Journal of Ethnopharmacology, vol. 94, no. 1, pp. 93-100, 2004.

[12] M. L. O. Souza-Formigoni, M. G. M. Oliveira, M. G. Monteiro, N. G. da Silveira-Filho, S. Braz, and E. A. Carlini, "Antiulcerogenic effects of two Maytenus species in laboratory animals," Journal of Ethnopharmacology, vol. 34, no. 1, pp. 21-27, 1991.

[13] L. A. Tiberti, J. H. Yariwake, K. Ndjoko, and K. Hostettmann, "Identification of flavonols in leaves of Maytenus ilicifolia and M. aquifolium (Celastraceae) by LC/UV/MS analysis," Journal of Chromatography B, vol. 846, no. 1-2, pp. 378-384, 2007.

[14] J. H. Y. Vilegas, F. M. Lanças, J. N. Wauters, and L. Angenot, "Characterization of adulteration of 'Espinheira santa' (Maytenus ilicifolia and Maytenus aquifolium, Celastraceae) hydroalcoholic extracts with Sorocea bomplandii (Moraceae) by high-performance thin layer chromatography," Phytochemical Analysis, vol. 9, no. 6, pp. 263-266, 1998.
[15] L. M. Souza, T. R. Cipriani, M. Iacomini, P. A. J. Gorin, and G. L. Sassaki, "HPLC/ESI-MS and NMR analysis of flavonoids and tannins in bioactive extract from leaves of Maytenus ilicifolia," Journal of Pharmaceutical and Biomedical Analysis, vol. 47, no. 1, pp. 59-67, 2008.

[16] R. Bruni, D. Rossi, M. Muzzoli et al., "Antimutagenic, antioxidant and antimicrobial properties of Maytenus krukovii bark," Fitoterapia, vol. 77, no. 7-8, pp. 538-545, 2006.

[17] J. C. R. Vellosa, N. M. Khalil, V. A. F. Formenton et al., "Antioxidant activity of Maytenus ilicifolia root bark," Fitoterapia, vol. 77, no. 3, pp. 243-244, 2006.

[18] L. M. de Souza, T. R. Cipriani, C. F. Sant'Ana, M. Iacomini, P. A. J. Gorin, and G. L. Sassaki, "Heart-cutting two-dimensional (size exclusion $\times$ reversed phase) liquid chromatography-mass spectrometry analysis of flavonol glycosides from leaves of Maytenus ilicifolia," Journal of Chromatography A, vol. 1216, no. 1, pp. 99-105, 2009.

[19] I. Molnár-Perl and Z. Füzfai, "Chromatographic, capillary electrophoretic and capillary electrochromatographic techniques in the analysis of flavonoids," Journal of Chromatography A, vol. 1073, no. 1-2, pp. 201-227, 2005.

[20] F. Xu, Y. Liu, R. Song, H. Dong, and Z. Zhang, "HPLC/DAD comparison of sixteen bioactive components between DaCheng-Qi decoction and its parent herbal medicines," Natural Product Communications, vol. 5, no. 6, pp. 893-896, 2010.

[21] L. Chi, Z. Li, S. Dong, P. He, Q. Wang, and Y. Fang, "Simultaneous determination of flavonoids and phenolic acids in Chinese herbal tea by beta-cyclodextrin based capillary zone electrophoresis," Microchimica Acta, vol. 167, no. 3-4, pp. 179185, 2009.

[22] Farmacopéia Brasileira, fascículo 4, parte II, Atheneu, São Paulo, Brazil, 4th edition, 2003.

[23] P. Poukens-Renwart, M. Tits, J. N. Wauters, and L. Angenot, "Densitometric evaluation of spiraeoside after derivatization in flowers of Filipendula ulmaria (L.) Maxim," Journal of Pharmaceutical and Biomedical Analysis, vol. 10, no. 10-12, pp. 1085-1088, 1992.

[24] M. Sannomiya, W. Vilegas, L. Rastrelli, and C. Pizza, "A flavonoid glycoside from Maytenus aquifolium," Phytochemistry, vol. 49, no. 1, pp. 237-239, 1998.

[25] W. Vilegas, M. Sanommiya, L. Rastrelli, and C. Pizza, "Isolation and structure elucidation of two new flavonoid glycosides from the infusion of Maytenus aquifolium leaves. Evaluation of the antiulcer activity of the infusion," Journal of Agricultural and Food Chemistry, vol. 47, no. 2, pp. 403-406, 1999.

[26] T. J. Mabry, K. R. Markham, and M. B. Thomas, The Systematic Identification of Flavonoids, Academic Press, New York, NY, USA, 1970. 


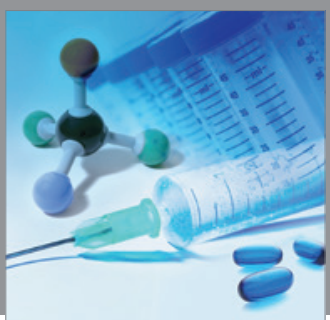

International Journal of

Medicinal Chemistry

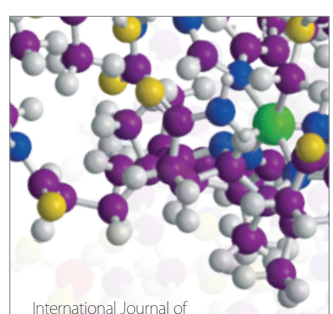

Carbohydrate Chemistry

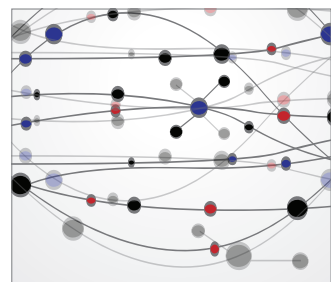

The Scientific World Journal
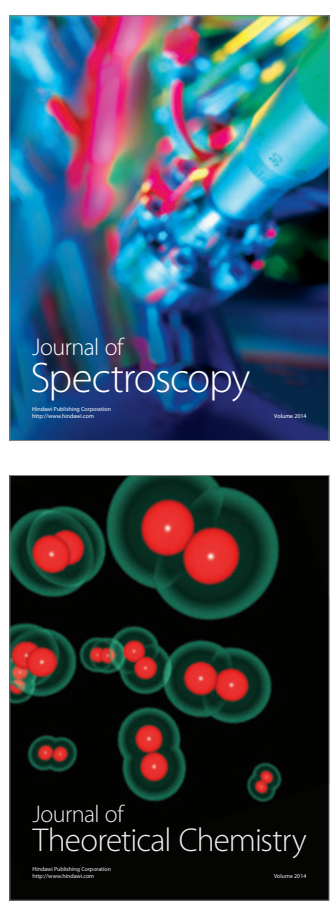
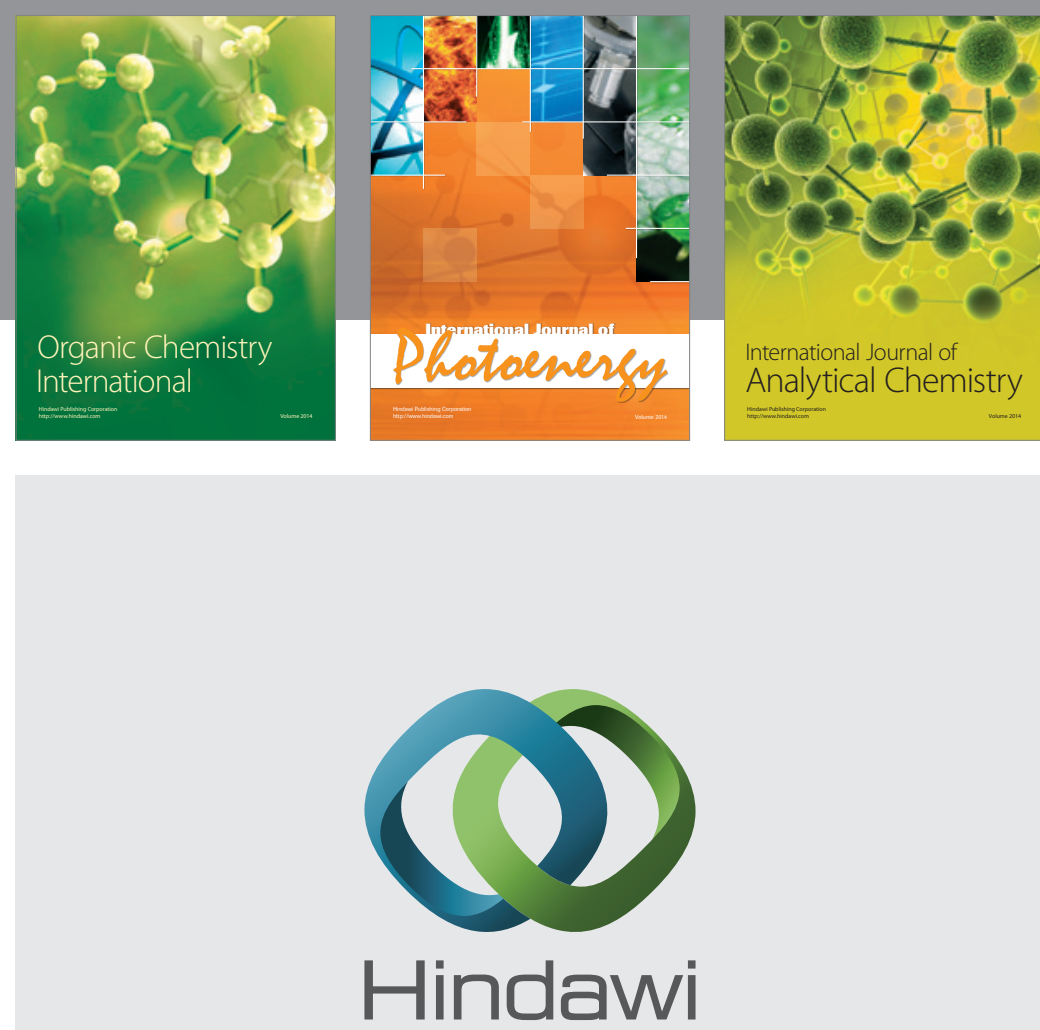

Submit your manuscripts at

http://www.hindawi.com
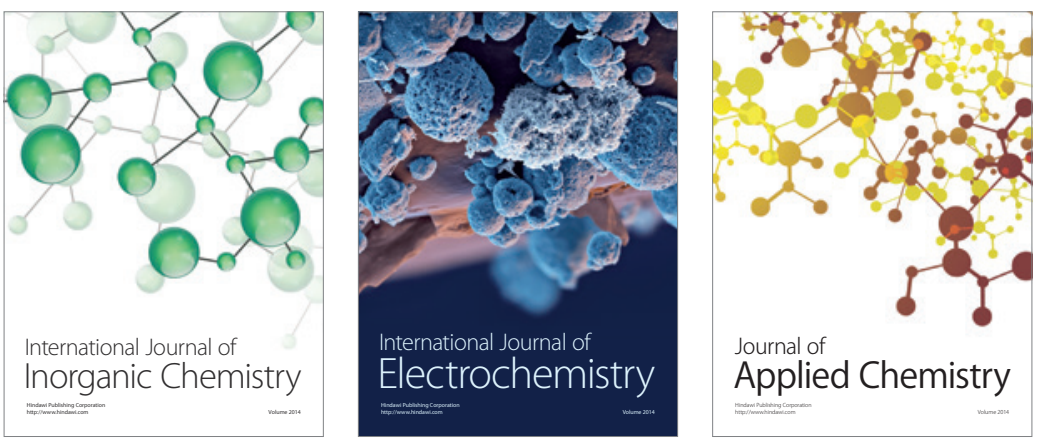

Journal of

Applied Chemistry
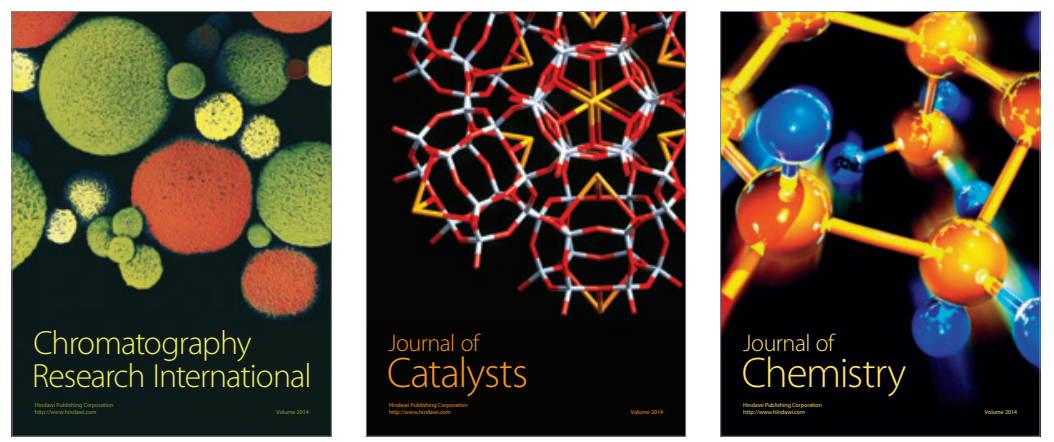
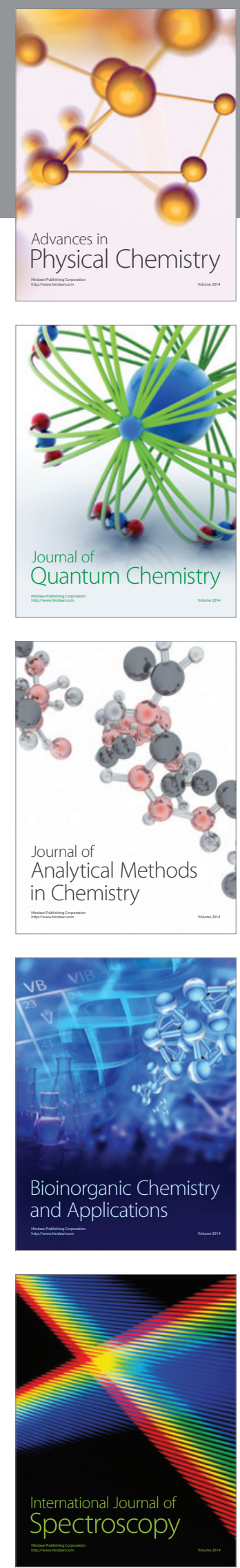